\title{
An Experimental Study on the Performance Characteristics of a Diesel Engine Fueled with ULSD-Biodiesel Blends
}

\author{
Viet Dung Tran ${ }^{a, 1}$, Anh Tuan Le ${ }^{\mathrm{b}}$, Anh Tuan Hoang ${ }^{\mathrm{c}, 1}$ \\ ${ }^{a}$ The Maritime College I, Haiphong, Vietnam \\ ${ }^{b}$ Hanoi University of Science and Technology, Hanoi, Vietnam \\ 'Ho Chi Minh City University of Technology (HUTECH), Ho Chi Minh City, Vietnam
}

\begin{abstract}
As a rule, the highest permissible sulfur content in the marine fuel must drop below 0.5\% from 1 January 2020 for global fleets. As such, ships operating in emission control areas must use low sulfur or non-sulfur fuel to limit sulfur emissions as a source of acid rain. However, that fact has revealed two challenges for the operating fleet: the very high cost of ultra-low sulfur diesel (ULSD) and the installation of the fuel conversion system and the ULSD cooling system. Therefore, a solution that blends ULSD and biodiesel (BO) into a homogeneous fuel with properties equivalent to that of mineral fuels is considered to be significantly effective. In the current work, an advanced ultrasonic energy blending technology has been applied to assist in the production of homogeneous ULSD-BO blends (ULSD, B10, B20, B30, and B50 with blends of coconut oil methyl ester with ULSD of $10 \%, 20 \%, 30 \%$ and $50 \%$ by volume) which is supplied to a small marine diesel engine on a dynamo test bench to evaluate the power and torque characteristics, also to consider the effect of BO fuel on specific fuel consumption exhaust gas temperature and brake thermal efficiency. The use of the ultrasonic mixing system has yielded impressive results for the homogeneous blend of ULSD and BO, which has contributed to improved combustion quality and thermal efficiency. The results have shown that the power, torque, and the exhaust gas temperature, decrease by approximately $9 \%, 2 \%$, and $4 \%$ respectively with regarding the increase of the blended biodiesel rate while the specific fuel consumption and brake thermal efficiency tends to increase of around $6 \%$ and $11 \%$ with those blending ratios.
\end{abstract}

Keywords: ULSD, biodiesel, engine performance, IMO 2020 Sulphur-cap, marine diesel engine

Article History: Received: 30th Oct 2020; Revised: 20th Nov 2020; Accepted: 25 th Nov 2020; Available online: 27th Nov 2020

How to Cite This Article: Tran, V.D., Le, A.T., Hoang, A.T. (2021) An Experimental Study on the Performance Characteristics of a Diesel Engine Fueled with ULSD-Biodiesel Blends. Int. Journal of Renewable Energy Development, 10(2), 183-190

https://doi.org/10.14710/ijred.2021.34022

\section{Introduction}

The International Maritime Organization (IMO) regulates the mandatory use of very low sulfur fuels in sea transport from January 1, 2020. This regulation, commonly known as the "IMO 2020 Sulphur Cap", is part of the IMO 2020 Program, which aims to reduce sulfur emissions from ocean shipping by $80 \%$ (Nguyen et al. 2020). Compliance with new regulations on sulfur content in fuels used by ships, when operating in emissions control areas, can be made using a fuel with a sulfur content of $0.1 \%$ always of the vessel's operation or switching from a high sulfur fuel to a $0.1 \%$ sulfur fuel when the vessel enters the emission control area. Several studies have shown that fuel conversion during ships' operation could have several problems related to the properties of the fuel such as viscosity, lubricity, flash point, ignition, and combustion quality (Hoang et al. (2019))(Mangus et al. (2015)). Regulations around the world are beginning to require the use of ultra-low sulfur fuels. In the United States, this requirement has been applied to automotive engines, it will be applied to train engines and eventually to marine engines. Marine engines that comply with EPA Tier 4 emissions standards require the use of ultra-low sulfur (ULSD) fuels. The EPA predicts that the introduction of the new regulations will promote a reduction in sulfur content in commercially available fuels (Hoang (2018)).

Furthermore, the biggest challenge is that the low viscosity of the fuel can cause leaks in the fuel feed pump and the high-pressure pump, resulting in a decrease in the amount of oil supplied to the engine and consequently affect the functioning of the engine. Accordingly, fuels with a sulfur content up to $0.0015 \%$ are called Ultra Low Sulphur Diesel ULSD fuels, up to $0.05 \%$ are low sulfur diesel (Low Sulphur Diesel) and up to $0,5 \%$ is conventional diesel (Sentorun et al. (2011)). Also, they proposed recommendations for carbon steel corrosion when using ULSD fuel in diesel engines. Therefore, on the fleet using ULSD fuel, a cooling system must be equipped to overcome the disadvantage of too low viscosity of this fuel. For example, Geng et al. (Geng et al. (2016)) studied and designed the MGO fuel cooling system for ships operating in the ECA emission control area. This system is installed in front of the pumps supplying fuel to the engine, the indirect fuel cooling system through the chilling cooling cluster, and the freshwater circulation

${ }^{1}$ Corresponding author: dungtranviet1979@gmail.com and hatuan@hutech.edu.vn 
pumps. This system has been installed on cargo ships that are equipped with MAN \& BW engines. Besides, (Geng et al. (2017)) conducted a study to evaluate the effect of ULSD fuel on the combustion performance and emission characteristics $\left(\mathrm{NOx}\right.$ and $\mathrm{CO}_{2}$ ) of diesel generators with the speed of $50 \%$ - $90 \%$ rated speed and torque of $25 \%$ $100 \%$. The results showed that the in-cylinder pressure and the heat release rate increased slightly with increasing load, while the burning time was longer due to the earlier combustion. With the increase of speed and load, the fuel consumption decreased slightly while the exhaust gas temperature rose modestly. $\mathrm{NOx}$ and $\mathrm{CO}_{2}$ emissions increased according to the growth of load and speed when tested with ULSD (Hoang and Pham (2019))(Seraç et al. (2020)). Thus, the direct use of ULSD fuel was feasible on the fuel supply system that added the fuel cooling system.

However, the installation cost was very high. Moreover, the corrosive properties of the ULSD fuel were a difficult problem to solve when the sulfur content in the fuel was very low. Therefore, the combination of ULSD fuel with too low viscosity and biodiesel (BO) with high viscosity could produce a new fuel that brought suitable viscosity and reduction of operating costs (Dhahad, Chaichan, and Megaritis (2019))(Mattson et al. (2019)). Although the anti-wear and lubrication properties of the fuel were reduced after treatment, which could be restored by blending ULSD with 1-2 vol\% biodiesel as the results of the study by Zhu et al. (2010). Other properties that might be affected include cetane number, cloud point (CP), pour point, and kinematic viscosity. Accordingly, the blending of Biodiesel with ULSD would have changes in fuel properties compared to ULSD. (Hoang, 2019) investigated the effect of blending ULSD with various biodiesel on cold storage stability. This study has shown that the $\mathrm{CP}$ of the blend was correlated with the blending ratio according to the quadratic polynomial equations. In contrast, another report (Bari (2014)) found that a linear increase in CP was associated with an increase in the blend ratio of biodiesel with ULSD. (Seraç et al. (2020)) and (Onlamnao, Phromphithak, and Tippayawong (2020)) investigated the effect of low temperature on the kinetic viscosity of a soybean methyl ester (SME) blending with ULSD. These experimental data demonstrated a linear curve relationship between kinematic viscosity at $40^{\circ} \mathrm{C}$ and the blending ratio of biodiesel and ULSD. (Pham et al. 2018) conducted experimental studies by examining liquid flow at low temperature, cold filter plugging point and the cloud point of 7 different biofuels blending with ULSD to provide data on the liquid-cooled flow of ULSD used in diesel engines. Andrew M. Duncan (Duncan 2012) predicted that after blending ULSD with Biodiesel at the rates of $5,10,20,40,80 \%$, the viscosity of the fuel achieved optimal results with the ratio of 5, 10 and $20 \%$ biodiesel. The viscosity of the different blends increased by about $164 \%$ at ambient pressure and $373.15 \mathrm{~K}$ and $547 \%$ at $283.15 \mathrm{~K}$ and the highest pressure (131Mpa). (Gude, (2013)) used a mixture of ULSD and biodiesel from waste cooking oil. The results showed that combustion products of WCOB5 (5\% waste cooking oil+95\% ULSD), WCOB10, WCOB20 and WCOB30 revealed the reduction of the PAHs emission, particle emission, hydrocarbon and carbon monoxide by $7.53 \%-37.5 \%, 5.29 \%-8.32 \%, 10.5 \%$ $36.0 \%$ and $3.33 \%-13.1 \%$ respectively in comparison to ULSD (Hoang and Le (2017)). (Mangus et al. (2015)) has tested on four biodiesel fuels blended with ULSD fuel at the rates of $5 \%, 10 \%, 20 \%$ and $50 \%$ on common rail engines. The results of the study showed that the fuel viscosity, the energy density and the molecular structure of the fuels had different effects on the combustion process. When adjusting the burning time, blended biodiesel fuels were shown to reduce NOx emissions compared to ULSD fuel. The obtained experimental data also showed that there is a clear change in the combustion mechanism when increasing the rate of biodiesel fuel.

However, the homogeneous quality of blended fuel depends mainly on the mixing method. Currently, the fuel mixing technology used mainly is mechanical mixing by the turbine stirring method, but the quality is quite acceptable and long mixing time (Putro et al. (2020)). Meanwhile, the solution using ultrasonic waves to generate pulses from bubbles of 2 liquid phases is considered as a very potent solution to improve the homogeneous quality of the 2-liquid blend such as ULSD and Biodiesel. Hielscher Ultrasound Technology introduced Hielscher's ultrasonic fuel blending technology with the ability to blend 500 gallons at 1-2 gallons $/ \mathrm{min}$. The process of mixing biofuel and ULSD is continuous and ensures consistent quality according to US fuel standards. Hoang (2019) used ultrasonic energy in the production of ULSD-biofuel blends, the results illustrated that ultrasonic energy was considered as the most effective tool to optimize the biodiesel production process. Therefore, the mixing of ULSD and biodiesel (BO) into a homogeneous fuel, with a viscosity similar to that of traditional diesel fuel by using ultrasonic is a very effective solution. In general, on marine diesel engines switching to use ULSD based on biodiesel has a great practical significance, especially for environmental protection and the operational cost. In this study, a test on a diesel engine using a ULSD blending with coconut oil methyl ester (BO) assisted by ultrasonic energy was conducted to examine the power, torque, specific fuel consumption and exhaust gas temperature.

\section{Materials and Methods}

\subsection{Fuels}

Commercial ULSD fuel (diesel $0.001 \%$ S) and biodiesel based on coconut oil methyl ester are blended at the rate of 10\% (B10), 20\% (B20), 30\% (B30), 50\% (B50). Fuel blends between ULSD and biodiesel have been made with ultrasonic energy assistance. The ULSD and coconut oil continuous blending unit is produced based on ultrasonic generators. A continuous mixing device ensures a continuous supply of the engine and a balance between the amount of fuel fed into the mixing unit and the fuel consumption of the engine. The operating principle of the ultrasonic fuel mixing system is illustrated in Fig. 1. After mixing with ultrasonic energy with a frequency of $28 \mathrm{kHz}$ and an ultrasonic power of $100 \mathrm{~W}$ at a height of $90 \mathrm{~mm}$ of the distance from the ultrasonic horn to the bottom of the emulsifying chamber gave high stability. This mixing system produced ULSD-BO emulsion with the highest stability of $98.5 \%$ after 17 minutes. Furthermore, an improvement in fuel injection characteristics such as the penetration length and cone angle of the spraying was confirmed in the study (Hoang et al. (2019)) which has performed simulate the use of ultrasonic energy for 
blending ULSD and BO fuels. Furthermore, (Duncan et al. (2012)) studied a biofuel blending system of crude palm oil and free fatty acids by combining a mixer and intense ultrasonic waves. With power output up to $1000 \mathrm{~W}$ and continuous operation at $18 \mathrm{kHz}$ in a $100 \mathrm{ml}$ mixer. The results showed that after 20 seconds of the fuel residing in the mixing chamber, the mixing ratio reached $92.5 \%$. The quality of the blended biofuel fully has met the ASTM D6751 biodiesel specification. The ULSD-BO emulsion generated by ultrasonic waves provides fuel with an extremely low sulphur content and an increased oxygen content. This emulsion has met the increasingly stringent requirements of IMO regulations, as well as meeting engine manufacturers' recommendations for fuel used in marine diesel engines. The physical and chemical properties of the tested fuels are described in Table 1. This result shows that the fuel mixing system by ultrasonic energy completely meets the quality criteria of the blended fuel. Interestingly, it demonstrates the advantages of mixing time and uniformity of fuel compared to mechanical stirring methods.

\subsection{Testing methods and procedures}

The test bench is controlled via PUMA software which is connected to a PC. PUMA software has the function of recording the signals from sensors mounted on the testbed and engine through the Cable boom converter box. The sensor signals are converted to the monitor to help the operator to control the working process of the engine. The process of changing speed, torque, and position of fuel gear is carried out through the K57 control panel. A diagram of the ETB high dynamic test bench is shown in Fig. 2. Moreover, the test system includes the following main equipment: APA 100 electric brake, AVL 554 lubricant cooling equipment, AVL 553 cooling water cooler, AVL $733 \mathrm{~S}$ fuel consumption measuring device, AVL 753 fuel temperature stabilizer, and throttle controller THA 100. The D243 engine is a diesel engine with 4 cylinders in line, 4 strokes, water-cooled, direct injection, the working order of 1-3-4-2, and no turbocharging. Specifications of the D243 diesel engine are given in Table 2. The engine uses a closed-loop one-loop forced-water cooling system, with a centrifugal water pump, a suspension valve. The camshafts are located in the body and have a cam profile of a three-arc convex cam. Before measuring the output parameters, some steps should be done: the engine run at no-load for 10 minutes and using only DO fuel, then check the stability of the engine parameters; Check the operation status of the equipment measuring parameters. Next, the engine works at a 50\% load and speed of 1500 rpm for 30 minutes to stabilize the thermal status. Criteria for evaluating stable working: The measuring parameters are stable, fluctuation of the measured parameters is small. After the engine works stably, measuring the performance characteristics, specific fuel consumption, and exhaust gas temperature of the D243 engine with different fuels according to the external characteristics at $100 \%$ load of 1000, 1200, 1400, 1500, 1600, 1800, and $2000 \mathrm{rpm}$. Each measurement point for 05 types of fuel is performed 03 times and take the average result.

Table 1

Properties of the test fuels

\begin{tabular}{lcccccc}
\hline Properties & \multicolumn{5}{c}{ Fuels } & Test method \\
\cline { 2 - 6 } & ULSD & B10 & B20 & B30 & B50 & (ASTM) \\
\hline Density @ 15 ${ }^{\circ} \mathrm{C}, \mathrm{kg} / \mathrm{m}^{3}$ & 838.8 & 846.4 & 850.3 & 856.2 & 861.8 & D1298 \\
Kinematic viscosity @ $40^{\circ} \mathrm{C}, \mathrm{mm}^{2} / \mathrm{s}$ & 3.34 & 3.524 & 3.882 & 4.116 & 4.425 & $\mathrm{D} 445$ \\
Surface tension @ 30 $\mathrm{C}, \mathrm{N} / \mathrm{m}$ & 0.0258 & 0.0257 & 0.026 & 0.0264 & 0.0263 & D971 \\
Low calorific value, $\mathrm{MJ} / \mathrm{kg}$ & 42.8 & 42.03 & 41.65 & 41.06 & 40.5 & $\mathrm{D} 6751$ \\
Cetane number & 45 & 46.05 & 46.5 & 47.5 & 48 & D613 \\
Flash point, ${ }^{\circ} \mathrm{C}$ & 66 & 72.55 & 84.12 & 95.45 & 102.25 & D93 \\
\hline
\end{tabular}

Table 2

Specifications of D243 diesel engine

\begin{tabular}{ll} 
Type & 4 -stroke, 4 cylinders in line, direct injection, closed-loop \\
Model & cooling system, no turbocharging \\
Rated Power & D243 \\
Maximum speed & $56 \mathrm{~kW}$ \\
Bore/ Stroke & $2200 \mathrm{rpm}$ \\
Compression ratio & $110 \mathrm{x} 125 \mathrm{~mm}$ \\
\hline
\end{tabular}




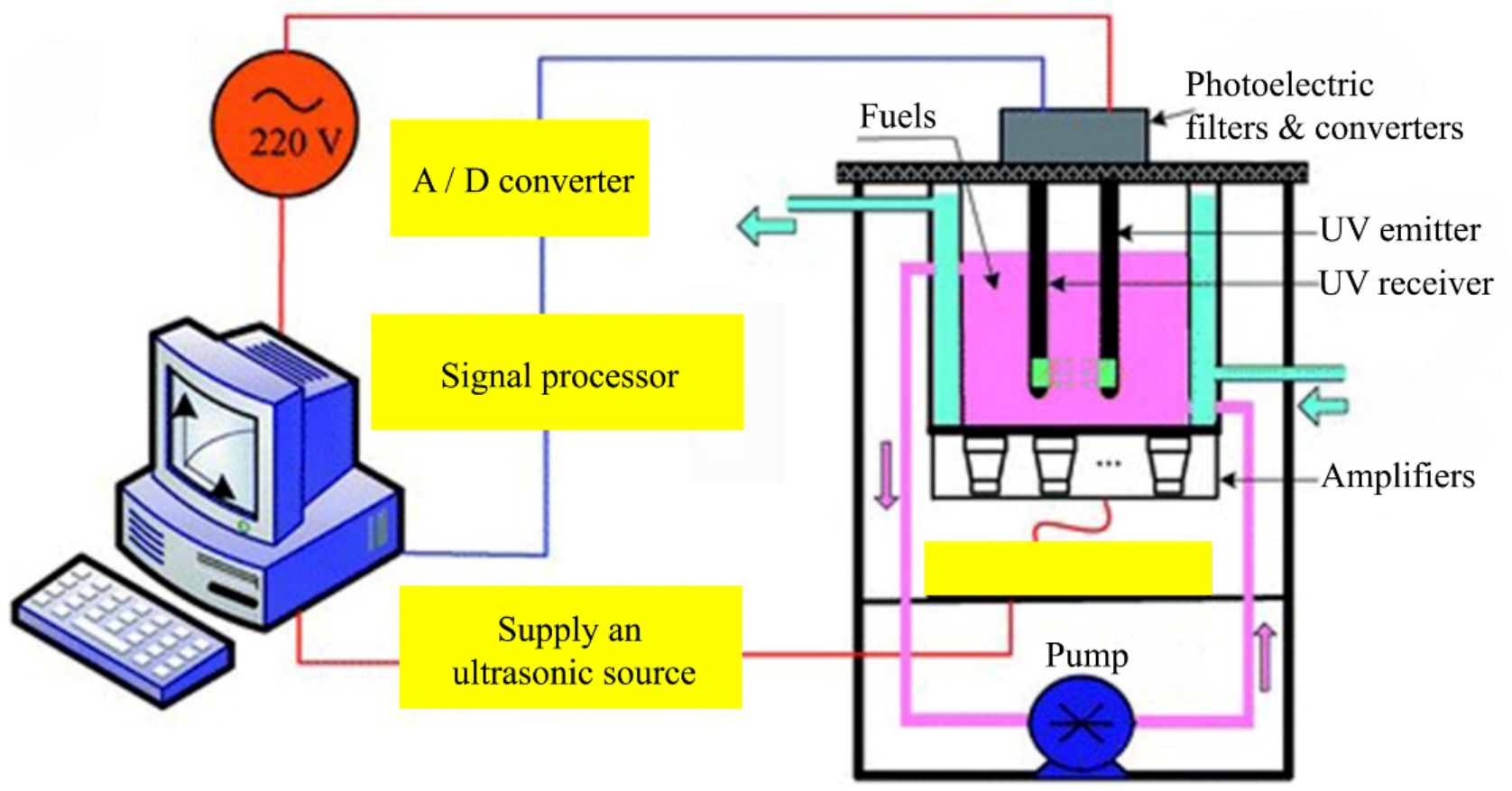

Fig. 1 The operating principle of the ultrasonic fuel mixing system

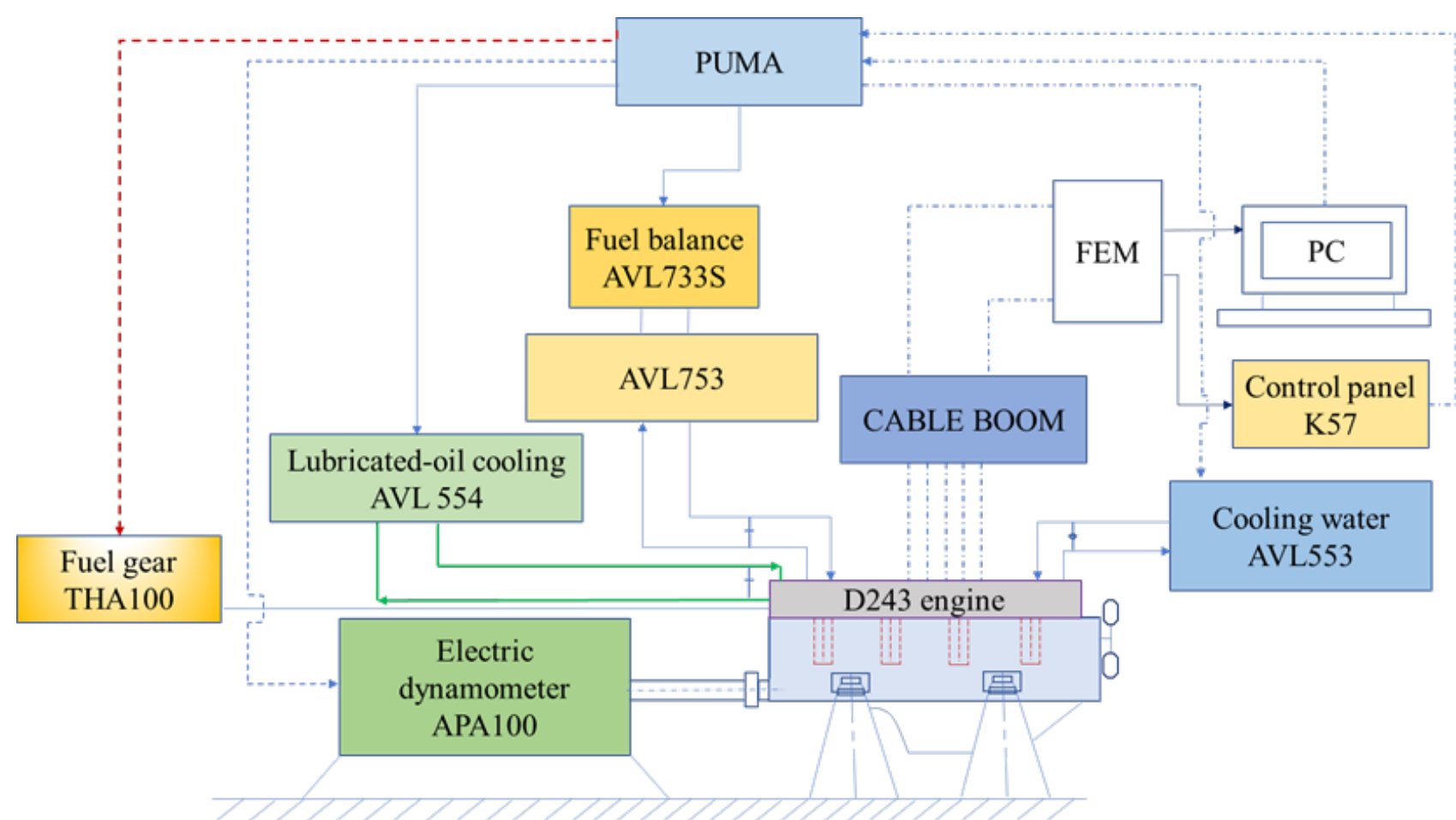

Fig. 2 Engine test bench with D243 diesel engine

\section{Results and discussion}

\subsection{Power and torque}

The total produced power in a diesel engine depends on the amount of fuel pumped, which can be efficiently combusted in the combustion chamber. Because of the lower calorific value of biodiesel in comparison to diesel fuel, the maximum produced power in an unmodified diesel engine fueled with biodiesel or its blends is generally lower than that of ultra-low sulfur diesel fuel. Also, the output brake power/torque of diesel engines fueled with biodiesel or its blends derived from various feedstocks are mostly lower than those of ultra-low sulfur diesel fuel, barring few exceptions. The extent of output power reduction changes according to various types of biodiesel. At all engine speeds, biodiesel's torque and power outputs are lower compared to fossil diesel fuel because the calorific value of biodiesel is $8-10 \%$ lower than 
that of ultra-low sulphur diesel fuel. Fig. 3 depicts the performance characteristics of an engine with a prominent feature of the tendency to decrease power as an increase of the biodiesel blending ratio. For example, at speeds of $2000 \mathrm{rpm}$ and full load, engine power using ULSD fuel is $10.5 \%$ higher than that of B50. With the same amount of fuel supplied to a cycle for all fuels, the lower calorific value of biodiesel leads to the reduction of power (Hoang and Le (2017)). On the other hand, the phenomenon of both burning and compression occurs because of reduced delay time when using biodiesel fuel result in reduced power. With more biodiesel participation rates, power decreases while specific fuel consumption increases slightly. It is an indisputable fact that the calorific value of biodiesel fuel is lower than that of ULSD. On average, the power with B10, B20, and B30 fuels in comparison to ULSD decreased by $-2.08 \%,-4.16 \%$, and $-6.00 \%$ respectively. Furthermore, the power increases dramatically for all tested fuels according to the rise in speed. The distillation properties, viscosity, and oxygen content of biodiesel influence the burning velocity and heat release rate, which improve the power characteristics of the test engine at higher speeds.

Fig. 4 shows the trend of the linearly increasing correlation of the biofuel blend ratio and torque. A reduction in torque is observed to be $-1.5 \%,-3.6 \%,-5.2 \%$ and $-8.4 \%$ for $\mathrm{B} 10, \mathrm{~B} 20, \mathrm{~B} 30$ and $\mathrm{B} 50$ respectively in comparison to ULSD. The cause can be attributed to an increase in the heat release rate with a higher biodiesel blend ratio through the combination of a hypothetical pair used to change heat release profiles. For a denser biodiesel blend, a greater amount of fuel is injected into the cylinder resulting in more absorption of the latent heat from the previous cycle.

More interestingly, a multi-component content of biofuel leads to atomization immediately and evaporation after injection. Therefore, energy is added in the cylinder through the immediate evaporation of the fuel. However, this assumption is not what is physically happening, but rather an artefact of the heat release model. For example, the observed duration of the injection shows that a biodiesel rich mixture has a longer injection time because more fuel is required for the biodiesel to achieve the same energy.

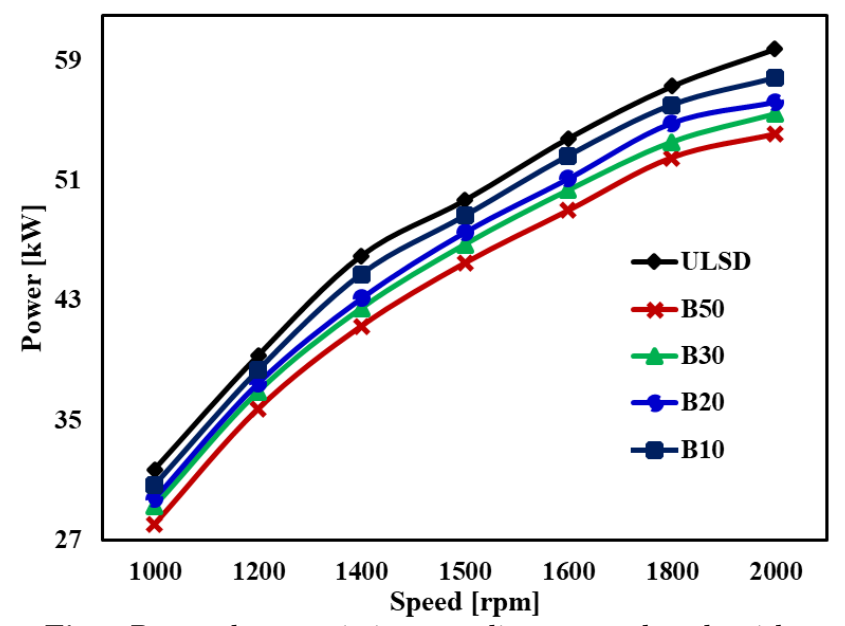

Fig. 3 Power characteristics according to speed mode with different types of test fuels

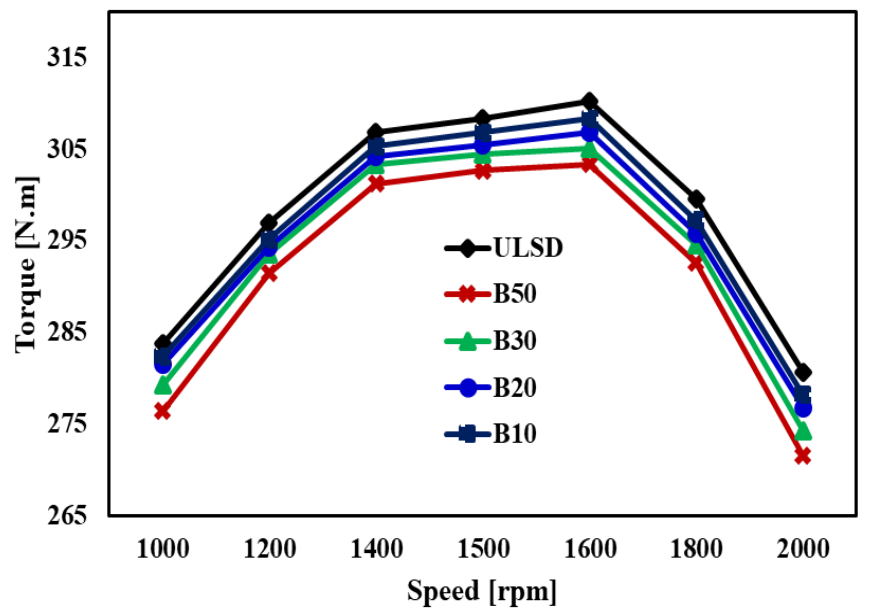

Fig. 4 Engine torque characteristics according to speed modes at $100 \%$ load of different fuels

The highest torque of all biodiesel blends occurs at the same specific speeds, found at $1600 \mathrm{rpm}$ in Fig. 4. This is because the combustion at this speed, which is predominantly pre-mixed, occurs at the same crank angles due to the combustion normalization techniques used in this study. As the percentage of biodiesel blends increases, the crank angle at which the maximum temperature occurs is delayed due to the effect of viscosity on the atomization. When a more viscous fuel leaves the injector, the fuel droplets are larger and do not evaporate efficiently.

This stresses the necessity to optimize the biodiesel mixing proportion in terms of achieving either similar or slightly increased engine performance compared to ultralow sulfur diesel fuel, which might be able to obtain by tuning/recalibrating the engine's fuel injection system. As a result, it is not a severe problem to address when introducing biodiesel as a potential fuel on a large-scale application in transportation means.

\subsection{Specific fuel consumption}

Specific fuel consumption (SFC) can be calculated by the engine torque, the engine speed, and the fuel mass consumption rate. SFC decreases with increasing load for all different fuels. Normally, increased brake thermal efficiency contributes to reduced SFC, while reduced fuel calorific value is thought to increase SFC. Typically, SFC is increased in the context of biodiesel-fuelled engines in comparison to diesel-fuelled engines, although there stand some exceptions. Higher biodiesel mass is thus supposed to release an equal amount of heat to diesel fuel in the cylinder due to higher density, but lower biodiesel calorific value as opposed to diesel fuel. For each test mode, the ratio of blended biodiesel in fuel is proportional to the SFC due to the lower heat value of biodiesel. Since the amount of fuel supplied to the cycle remains constant for the test fuels, a further decrease in power results in an increase in SFC. Compared to ULSD, the B50 had the highest average SFC gain of $5.68 \%$ at $1000 \mathrm{rpm}$ when the test was at full load. Meanwhile, at $1500 \mathrm{rpm}$, the largest difference (4.84\%) in SFC was seen in B30 compared to ULSD. Though the insignificant difference is detected between the SFC of engines operated with B20 and diesel fuel that has similarities with research results by Canakci and Van 
Gerpen (Canakci and Gerpen (2003)). Engine performance depends on the origin of the biodiesel, the different origin leads to some changes in the properties of the fuel, thus having different effects on the engine. Calorific value, methane number, and viscosity are the main properties that affect the engine. Fuel has a lower calorific value, resulting in reduced capacity and increased fuel consumption.

On the other hand, if the amount of fuel supplied remains unchanged, the air/fuel ratio of the engine using biodiesel can be higher than that of conventional diesel fuel. This difference is due to the available oxygenated compounds in biodiesel fuel itself. Meanwhile, with the same certain working mode of the engine, the amount of air fed into the cylinder is the same for all fuels (Kumar et al. (2016)). The result is a larger air/fuel ratio of biodiesel fuel. Furthermore, it is an indisputable fact that during the combustion, more biodiesel fuel needs to be supplied to ensure the same power. The reason is that biodiesel has a higher density while its calorific value is lower than that of conventional diesel. The reason is that the preoxygenation degradation reactions in biodiesel production have increased the oxygen content and the number of saturated C-C bonds, leading to a decrease in the calorific value and cetane number of the biofuel.

In general, Fig.5 depicted SFC of diesel engines running on biodiesels or its blends is slightly higher compared to that of ULSD fuel in most experiments, and SFC depends greatly on the injection strategy and fuel properties. As a result, test data has revealed a fairly strong increase in SFC for the B50 in comparison to ULSD, an increase of about 5-7\%. However, lower biodiesel blends increase SFC due to molecular oxygen in biodiesel components, which enhance the combustion process in the cylinder, resulting in the improvement of brake thermal efficiency. Additionally, biodiesel that is produced by using the peroxidation process is found to have higher oxygen content and a higher number of saturated carbon-to-carbon bonds. Nonetheless, the application peroxidation process is believed to reduce the calorific value and cetane number of biodiesel (Zha, Florea, and Jansons (2012)). Therefore, the SFC of the engine running on both biodiesels produced with and without the peroxidation process is higher than that of ULSD fuel in the reverse order of calorific value.

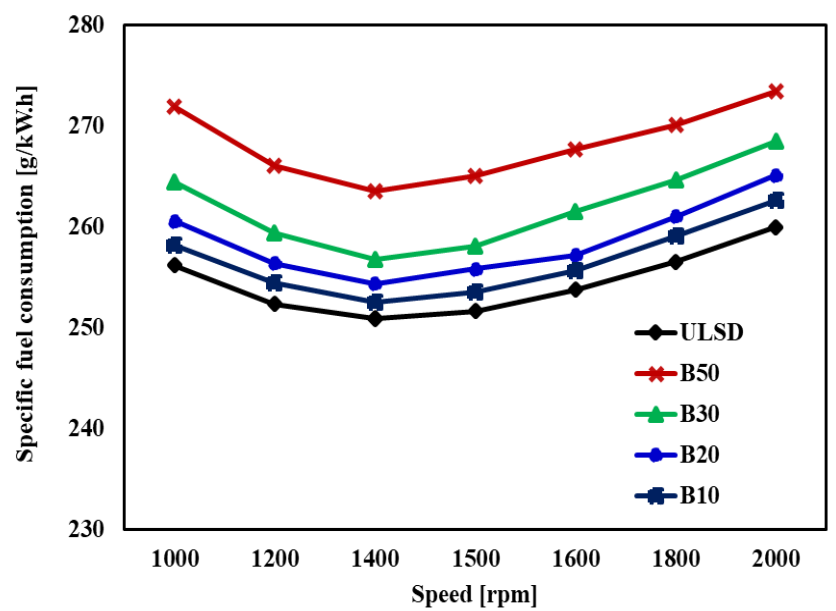

Fig. 5 Specific fuel consumption according to the speed mode at $100 \%$ load mode for different fuels

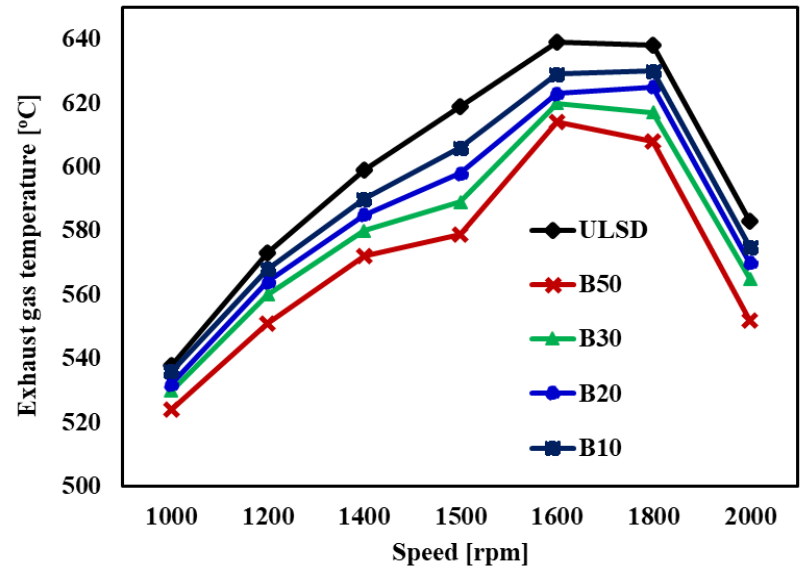

Fig. 6 Exhaust gas temperature according to the speed mode at full load for different fuels

\subsection{Exhaust gas temperature}

Exhaust gas temperature is one of the parameters that evaluate the quality and behavior of the combustion process. If engine parameters such as injection pressure, pressure in the cylinder at the end of compression, and the amount of intake air are constant, the exhaust gas temperature can depend only on the physical and chemical properties of the fuel. Therefore, the high exhaust gas temperature can be caused by an afterburning on the exhaust piping. The test result depicted in Fig. 6 shows that at high speed more pronounced difference in exhaust gas temperature was observed. Particularly, at $1500 \mathrm{rpm}$ saw the greatest difference in exhaust gas temperature between biofuel and ULSD. More prominently, at 1500 rpm, all blended biofuels exhibited a decrease in exhaust gas temperature compared to ULSD. The reason comes from the addition of oxygen and less aromatic hydrogen carbon content, which makes the combustion concentrated in the main combustion phase with less after-burn.

The findings of previous studies reported that the use of biodiesel resulted in an increase and decrease in the emission temperature (Hoang and Pham (2019)), (Ruina et al. (2019)) and (Fayad (2020)). Biodiesel with longer ignition delay and higher viscosity is thought to contribute to higher combustion temperatures. This is also related to the high cetane number of biodiesel, which has an impact on reducing the premixing time and increasing combustion efficiency. The increase in the biodiesel ratio in the blends decelerates the heating generation process during combustion and thus loweres the gas temperature.

\subsection{Brake thermal efficiency}

Brake thermal efficiency (BTE) is known as the ratio of brake power obtained to the fuel power supplied to the engine, BTE generally provides a basis to compare the effectiveness of fuel possessing different calorific values. Normally, the BTE of an engine fueled with biodiesel, particularly at high load, is higher in comparison with diesel fuel because the oxygen content of biodiesel is considered as improving the combustion efficiency, even for fuel-rich zones (Zhou, Cheung, and Leung (2013)). 


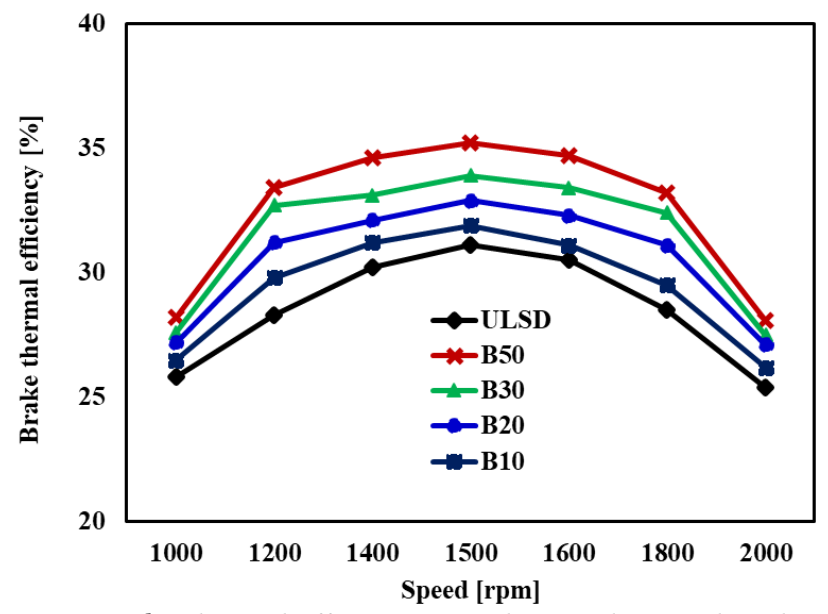

Fig. 7 Brake thermal efficiency according to the speed mode at $100 \%$ load mode for different fuels

This trend is due to the earlier start of the combustion of biodiesel at lower loads which prolongs the combustion duration and the shorter combustion duration at conditions with higher engine loads. Nonetheless, at lower engine speeds and loads, BTE for biodiesel is lower than ULSD fuel because the vaporization characteristics of biodiesel are relatively inferior at lower temperatures in the cylinder. In general, engine speeds, engine loads, and percentages of biodiesel-diesel blends have both positive and negative impacts on BTE, although $50 \%(\mathrm{v} / \mathrm{v})$ biodiesel blended with ULSD fuel can bring the optimal BTE. In summary, biodiesel from different feedstocks and their blends with diesel fuel and/or alcohols can deliver slightly higher BTE than diesel fuel, except in very few cases with lower BTE for biodiesel.

Fig. 7 reveals the outstanding advantage of ULSDbiodiesel blended fuels in terms of brake thermal efficiency (BTE). More interestingly, the BTE of the engine using the B50 has been improved by up to $4 \%$ compared with using ULSD at speeds of $1500 \mathrm{rpm}$. There is an increase in BTE with an increase in biodiesel content in the test fuel. The reason considered to be the basis for the above difference is due to the shorter $\mathrm{C}-\mathrm{C}$ chain structure of the biodiesel, which made the complete combustion process earlier. Another reason that cannot be ignored is that the addition of oxygen in biodiesel fuel has improved the main combustion quality of the engine. Several studies on using ULSD-biodiesel blends (Meng, Chen, and Wang (2008))(Lin, Hsu, and Chen (2011)) have shown that the results on BTE are consistent with the trends in this work.

\section{Conclusion}

Direct mixing of ULSD fuel with biofuel is considered an effective solution to improve the low viscosity properties of ULSD fuels. Besides, to ensure energy security for the shipping industry when fossil fuel resources are exhausted. There are a lot of fuel mixing technologies mentioned by studies, the most prominent recently being the technology that uses ultrasonic waves to mix fuels. Experimental experiments were conducted on a diesel engine using ULSD-biodiesel blends. The biodiesel used in this study is produced from coconut oil. Blended fuels with $10 \%, 20 \%, 30 \%$ and $50 \%$ by volume of biodiesel content $2 \%$,
$4 \%, 6 \%$ and $8 \%$ respectively of the oxygen in the blended fuel. Testing on speed mode with ULSD-Biodiesel blended fuels yielded the following conclusions about the engine performance:

- The power and torque of the engine when using biodiesel fuels have seen a decrease by $3-6 \%$ in comparison to ULSD. Therefore, maintaining engine power should be addressed by increasing the blended fuel feed volume.

- Compared with ULSD, the use of ULSD-biodiesel blend fuels resulted in an approximately $2-5 \%$ increase in specific fuel consumption, mainly due to the lower low calorific value of biodiesel compared to ULSD.

- The exhaust gas temperature is a testament to improving combustion as well as reducing the number of toxic substances in the combustion of ULSD-biodiesel fuel.

In conclusion, the use of biodiesel blended with ULSD supported by ultrasonic waves has brought positive effects to reduce the economic pressure on fleets to switch to ULSD fuel to respond meeting "IMO 2020 sulfur cap" with little impact on engine efficiency. In the future, it is quite interesting to study the effects of the mixing ratio as well as the injection pressure on the fuel spraying development characteristics in real conditions in the combustion chamber.

\section{References}

Bari, S. (2014) Performance, Combustion and Emission Tests of a Metro-Bus Running on Biodiesel-ULSD Blended (B20) Fuel. Applied Energy, 124, 35-43. https://doi.org/10.1016/j.apenergy.2014.03.007.

Canakci, M and Jon, H.V.G. (2003) Comparison of Engine Performance and Emissions for Petroleum Diesel Fuel, Yellow Grease Biodiesel, and Soybean Oil Biodiesel. Transactions of the ASAE, 46(4), 937-944.

Dhahad, H.A., Miqdam, T.C. and Megaritis, T. (2019) Performance, Regulated and Unregulated Exhaust Emission of a Stationary Compression Ignition Engine Fueled by Water-ULSD Emulsion. Energy, 181, 10361050.

Duncan, A.M., Noorbahiyah, P., Christopher, D. D., Aaron, M S. and Susan, M. S-W. (2012) High-Pressure Viscosity of Soybean-Oil-Based Biodiesel Blends with Ultra-LowSulfur Diesel Fuel. Energy \& Fuels, 26(11), 7023-7036.

Fayad, M. A. (2020) Effect of Renewable Fuel and Injection Strategies on Combustion Characteristics and Gaseous Emissions in Diesel Engines. Energy Sources, Part A: Recovery, Utilization, and Environmental Effects, 42(4): 460-470.

Geng, P., Hongjun, M., Yanjie, Z., Lijiang, W., Kun, Y., Ji, J. and Tingkai, C. (2017) Combustion Characteristics and NOx Emissions of a Waste Cooking Oil Biodiesel Blend in a Marine Auxiliary Diesel Engine. Applied Thermal Engineering, 115, 947-954.

Geng, P., Qinming, T., Chunhui, Z., Lijiang, W., Xianzhong, H., Erming, C. and Kai, J. (2016) Experimental Investigation on NOx and Green House Gas Emissions from a Marine Auxiliary Diesel Engine Using Ultralow Sulfur Light Fuel. Science of the Total Environment, 572, 467-475.

Gude, V. G. and Georgene, E. G. (2013) Biodiesel from Waste Cooking Oils via Direct Sonication. Applied Energy, 109, 135-144. https://doi.org/10.1016/j.apenergy.2013.04.002.

Hoang, A.T. and Pham, V.V. (2019) A Study of Emission 
Characteristic, Deposits, and Lubrication Oil Degradation of a Diesel Engine Running on Preheated Vegetable Oil and Diesel Oil." Energy Sources, Part A: Recovery, Utilization and Environmental Effects, 4(5), 611-625. https://doi.org/10.1080/15567036.2018.1520344.

Hoang, A. T. (2019) Experimental Study on Spray and Emission Characteristics of a Diesel Engine Fueled with Preheated Bio-Oils and Diesel Fuel. Energy, 171, 795-808. https://doi.org/10.1016/j.energy.2019.01.076.

Hoang, A. T. and Le, V. V. (2017) The Performance of A Diesel Engine Fueled With Diesel Oil, Biodiesel and Preheated Coconut Oil. International Journal of Renewable Energy Development, 6(1), 1-7.

Hoang, A. T. and Pham, V. V. (2018) A Review on Fuels Used for Marine Diesel Engines. Journal of Mechanical Engineering Research \& Developments, 41(4), 22-32. https://doi.org/10.26480/jmerd.04.2018.22.32.

Hoang, A. T. and Pham, V. V. (2019) A Study of Emission Characteristic, Deposits, and Lubrication Oil Degradation of a Diesel Engine Running on Preheated Vegetable Oil and Diesel Oil. Energy Sources, Part A: Recovery, Utilization, and Environmental Effects, 41(5), 611-625. https://doi.org/10.1080/15567036.2018.1520344.

Hoang, A. T. and Tran, V. D. (2019) Experimental Analysis on the Ultrasound-Based Mixing Technique Applied to Ultra-Low Sulphur Diesel and Bio-Oils. International Journal on Advanced Science, Engineering and Information Technology, 9(1), 307-313.

Hoang, A. T., Tran, V. D., Dong, V. H. and Le, A. T. (2019) An Experimental Analysis on Physical Properties and Spray Characteristics of an Ultrasound-Assisted Emulsion of Ultra-Low-Sulphur Diesel and Jatropha-Based Biodiesel. Journal of Marine Engineering \& Technology. https://doi.org/10.1080/20464177.2019.1595355.

Kumar, B, R., Saravanan, S., Rana, D. and Nagendran, A. (2016) A Comparative Analysis on Combustion and Emissions of Some next Generation Higher-Alcohol/diesel Blends in a Direct-Injection Diesel Engine. Energy Conversion and Management, 119, 246-256.

Lin, Y. C., Kuo, H. H. and Chung, B. C. (2011) Experimental Investigation of the Performance and Emissions of a Heavy-Duty Diesel Engine Fueled with Waste Cooking Oil Biodiesel/ultra-Low Sulfur Diesel Blends. Energy, 36(1), 241-248. https://doi.org/10.1016/j.energy.2010.10.045.

Mangus, M., Farshid K., Jonathan, M., Daniel, T., James, P., Christopher, D., Edward, P. and Susan, S. W. (2015) Investigating the Compression Ignition Combustion of Multiple biodiesel/ULSD (Ultra-Low Sulfur Diesel) Blends via Common-Rail Injection. Energy, 89, 932-945.

Mattson, J., Nicolae, V. B., Christopher, D., Dan, M. and Nicolae, B. (2019) Second Law Analysis of Waste Cooking Oil Biodiesel versus ULSD during Operation of a CI Engine. Fuel, 255 https://doi.org/10.1016/j.fuel.2019.115753.

Meng, X., Guanyi, C. and Yonghong, W. (2008) Biodiesel Production from Waste Cooking Oil via Alkali Catalyst and Its Engine Test. Fuel Processing Technology, 89(9), 851-
857. https://doi.org/10.1016/j.fuproc.2008.02.006

Nguyen, H.P., Hoang, A. T., Sandro, N., Nguyen, X. P., Le, A. T., Luong, C. N., Chu, V. D. and Pham, V. V. (2020) The Electric Propulsion System as a Green Solution for Management Strategy of CO2 Emission in Ocean Shipping: A Comprehensive Review. International Transactions on Electrical Energy Systems e12580. https://doi.org/10.1002/2050-7038.12580.

Onlamnao, K., Sanphawat, P. and Nakorn, T. (2020) Generating Organic Liquid Products from Catalytic Cracking of Used Cooking Oil over Mechanically Mixed Catalysts. International Journal of Renewable Energy Development, 9(2), 159-166.

Pham, M. T., Hoang, A. T., Le, A. T., Al-Tawaha, A.R.M.S., Dong, V. H. and Le, V. V. (2018) Measurement and Prediction of the Density and Viscosity of Biodiesel Blends. International Journal of Technology, 9(5), 1015-1026. https://doi.org/10.14716/ijtech.v9i5.1950.

Putro, F. A., Sunu, H. P., Joko, W. and Setyawan, A. (2020) Thermodynamic Study of Palm Kernel Shell Gasification for Aggregate Heating in an Asphalt Mixing Plant. International Journal of Renewable Energy Development, 9(2), 311-317. https://doi.org/10.14710/ijred.9.2.311-317.

Ruina, L., Wang, Z., Ni, P. and Jiang, H (2019) Effects of Exhaust Gas Recirculation on the Particulates Structure Characteristics of Diesel Engine Fueled with Diesel/biodiesel Blend. Energy Sources, Part A: Recovery, Utilization, and Environmental Effects. https://doi.org/10.1080/15567036.2019.1646351.

Sentorun, S., Cigdem, Shyamal, K. S., Xiaoliang, M. and Chunshan, S. (2011) Mesoporous-Molecular-SieveSupported Nickel Sorbents for Adsorptive Desulfurization of Commercial Ultra-Low-Sulfur Diesel Fuel. Applied Catalysis B: Environmental, 101(3-4), 718-726. https://doi.org/10.1016/j.apcatb.2010.11.014.

Seraç, M. R., Selman, A., Adem, Y. and Seyfi, Ş. (2020) Evaluation of Comparative Combustion, Performance, and Emission of Soybean-Based Alternative Biodiesel Fuel Blends in a CI Engine. Renewable Energy, 148, 1065-1073. https://doi.org/10.1016/j.renene.2019.10.090.

Zha, K., Radu, C. F. and Marcis, J. (2012) Soot Evolution with Cyclic Crank-Angle-Resolved Two-Color Thermometry in an Optical Diesel Engine Fueled with Biodiesel Blend and ULSD. Journal of Engineering for Gas Turbines and Power 134 (9), 092803. https://doi.org/10.1115/1.4006710.

Zhou, J. H., Cheung, C. S. and Leung, C. W. (2013) Combustion, Performance and Emissions of ULSD, PME and B50 Fueled Multi-Cylinder Diesel Engine with Naturally Aspirated Hydrogen. International Journal of Hydrogen Energy 38(34), 14837-14848.

Zhu, L., Wugao, Z., Wei, L. and Zhen, Huang. (2010) Experimental Study on Particulate and NO X Emissions of a Diesel Engine Fueled with Ultra Low Sulfur Diesel, RME-Diesel Blends and PME-Diesel Blends. Science of the Total Environment, 408(5), 1050-1058. https://doi.org/10.1016/j.scitotenv.2009.10.056. 